\title{
Caracterização de isolados de Xanthomonas campestris pv campestris de sistemas de produção orgânico e reação de brássicas à podridão-negra
}

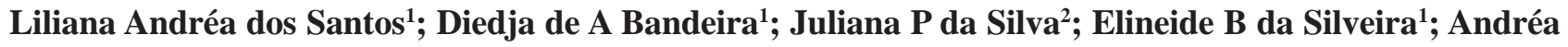 \\ Maria A Gomes'; Rosa de LR Mariano² \\ ${ }^{1}$ UFRPE-Depto. Biologia/Microbiologia, 52171-030 Recife-PE; ${ }^{2}$ UFRPE-Depto. Agronomia/Fitossanidade; elineidebs@yahoo.com.br
}

\section{RESUMO}

Noventa isolados de Xanthomonas campestris pv. campestris $(X c c)$ de brássicas oriundas de sistemas de produção orgânico das Zonas da Mata e Agreste de Pernambuco foram caracterizados com base na sensibilidade a antibióticos e sulfato de cobre e atividade de esterase. A maioria apresentou alta sensibilidade à tetraciclina $(76,6 \%)$, eritromicina $(63,3 \%)$ e estreptomicina $(63,3 \%)$, resistência à amoxicilina $(70 \%)$, gentamicina $(40,0 \%)$ e norfloxacin $(45,5 \%)$ e média sensibilidade $(44,4 \%)$ ou resistência $(44,4 \%)$ à neomicina. Cinqüenta e cinco isolados de $X c c$ foram resistentes ao sulfato de cobre na concentração de $50 \mathrm{mg} / \mathrm{mL}$ e todos foram sensíveis ao produto na concentração de $200 \mathrm{mg} / \mathrm{mL}$. Atividade de esterase foi apresentada por $92,22 \%$ dos isolados. A análise Euclidiana por ligação simples evidenciou variabilidade entre os isolados separando-os em sete grupos de similaridade. Foi estudada também a reação de 14 cultivares de brássicas à podridão-negra, utilizando o isolado 'B21' de $X c c$. As cultivares diferiram significativamente entre si em relação ao período de incubação, incidência e severidade final da doença. Os maiores valores de severidade final da doença foram verificados em brócolos 'Ramoso', couve-flor 'Bola de Neve' e 'Piracicaba de Verão', e repolho 'Chato de Quintal'. Os híbridos de couve-chinesa 'AF 70', 'AF 72', 'AF 69' e 'AF 66' mostraram-se altamente resistentes à doença, enquanto que brócolos 'Ramoso' e 'Precoce Piracicaba', couve-flor 'Piracicaba de Verão' e 'Híbrido Cindy' e repolho '60 Dias' foram medianamente resistentes.

Palavras-chave: Bactéria, variabilidade, resistência varietal, antibióticos, cobre.

\begin{abstract}
Characterization of strains of Xanthomonas campestris pv campestris from organic farming systems and reaction of brassicas to black rot
\end{abstract}

Ninety strains of Xanthomonas campestris pv. campestris (Xcc) from brassicas grown under organic farming systems in the 'Mata' and 'Agreste' regions of Pernambuco, Brazil, were characterized based upon sensitivity to antibiotics and copper sulfate, and esterase activity. Most of the strains showed high sensitivity to tetracycline (76.6\%), erythromycin $(63.3 \%)$ and streptomycin $(63.3 \%)$, resistance to amoxicilin $(70 \%)$, gentamicin $(40.0 \%)$ and norfloxacin $(45.5 \%)$ and medium sensitivity (44.4\%) or resistance (44.4\%) to neomycin. Fifty-five strains of Xcc were resistant to copper sulfate at $50 \mathrm{mg}$ $\mathrm{mL}^{-1}$ and all of them to $200 \mathrm{mg} \mathrm{mL}^{-1} ; 92.22 \%$ of the strains showed esterase activity. Strains were grouped in seven similarity groups by the Euclidean analysis-single linkage. The reaction of 14 genotypes of brassicas to strain 'B21' of Xcc was also studied. The genotypes significantly differed among them in relation to incubation period, incidence and disease severity. The highest disease severity was recorded on broccoli 'Ramoso', cauliflower 'Bola de Neve' and 'Piracicaba de Verão', and cabbage 'Chato de Quintal', classified as highly susceptible to black rot. The Chinese cabbage hybrids 'AF 70', 'AF 72', 'AF 69' and 'AF 66' were highly resistant to black-rot, while broccolis 'Ramoso' and 'Piracicaba Precoce', cauliflower 'Piracicaba de Verão' and 'Híbrido Cindy' and cabbage '60 Dias' showed intermediate resistance.

Keywords: bacteria, variability, genetic resistance, antibiotics, copper.

(Recebido para publicação em 12 de março de 2008; aceito em 17 de outubro de 2008) (Received in March 12, 2008; accepted in October 17, 2008)

$\mathrm{O}$ sistema de produção orgânico temse destacado como uma das atividades que mais se desenvolve em todo o mundo, ocupando o Brasil a segunda posição na América Latina, com estimativa de 800.000 ha de área manejada organicamente (Willer \& Yusefi, 2005). Em Pernambuco, na Zona da Mata, organizações não governamentais como SERTA (Serviço de Tecnologia Alternativa) e Centro Sabiá dão suporte ao desenvolvimento da agricultura familiar, incluindo a produção de hortaliças orgânicas.

Dentre as doenças bacterianas que afetam as brássicas nesse sistema de produção destaca-se a podridão-negra, causada por Xanthomonas campestris pv. campestris (Pammel) Dowson (Xcc). Os sintomas dessa doença podem ser observados em qualquer estádio de desenvolvimento da planta. Geralmente, as folhas apresentam lesões amarelas em forma de "V", com o vértice voltado para o centro, que progridem para a nervura principal, tornando-se necrosadas (Rodrigues Neto \& Malavolta Junior, 1995).

Em 2001, levantamentos em plantios orgânicos de brócolos (Brassica oleracea var. italica L.), couve-chinesa (Brassica pekinnensis L.), couve-flor (Brassica oleracea var. botrytis L.) e couve-manteiga (Brassica oleracea L. var. acephala DC.) no estado de Pernambuco, registraram elevadas prevalências da podridão- negra, sendo de até $88,9 \%$ em couve-flor. Isto indica a importância da podridãonegra para as culturas de brássicas em Pernambuco e destaca a adaptabilidade do patógeno aos ambientes e aos hospedeiros (Peruch et al., 2006).

Apesar do cultivo orgânico de hortaliças estar em franca expansão no Brasil, existe pouco conhecimento sobre esse sistema, incluindo os aspectos relacionados às doenças de plantas (van Bruggen, 2001). A expansão da produção orgânica de brássicas não foi acompanhada de estudos sobre a população de fitopatógenos e da reação de cultivares com resistência a doenças e adaptados a esse sistema. 
A variabilidade de populações de patógenos pode estar relacionada à adaptação a diferentes genótipos do hospedeiro, resposta a fungicidas e antibióticos, habilidade para tolerar substâncias tóxicas, utilizar substâncias para o crescimento e mudar a virulência em relação às plantas hospedeiras (Casela \& Guimarães, 1996). Alguns estudos têm constatado variabilidade de isolados de $X$. campestris em relação a antibióticos e produção de esterases (Adhikari \& Basnyat, 1999; Costa et al., 2001; Quezado-Duval et al., 2003).

A utilização de cultivares resistentes a doenças é uma das alternativas tecnológicas com maior sustentabilidade e possibilidade de adoção pelos agricultores orgânicos (Rodrigues et al., 2004). No Brasil, programas de melhoramento em brássicas visam a obtenção de híbridos e cultivares com maior resistência à podridãonegra, entre outras características (Henz et al., 1987). No entanto, as pesquisas estão voltadas principalmente para o sistema de produção convencional.

Os objetivos deste trabalho foram caracterizar isolados de Xcc de brássicas em sistema de produção orgânico nas Zonas da Mata e Agreste de Pernambuco, com base na sensibilidade a antibióticos e cobre e atividade de esterase, e avaliar a reação de cultivares à podridão-negra.

\section{MATERIAL E MÉTODOS}

\footnotetext{
Obtenção de isolados de Xanthomonas campestris pv. campestris - Os isolados de Xcc foram obtidos a partir de folhas de brássicas (brócolos, couve, couve-chinesa, couveflor e repolho) com sintomas de podridão-negra, coletadas em 15 áreas de plantio em sistema de produção orgânico nas Zonas da Mata (município de Glória de Goitá) e Agreste de Pernambuco (municípios de Gravatá, Chã Grande, Garanhuns). Das 15 áreas, $13(86,7 \%)$ caracterizavam-se como áreas de cultivo familiar com pouca diversidade de hortaliças e produção destinada a cooperativas, e apenas duas tinham mais de 2 ha, com produção vinculada a grandes supermercados. A maior parte das propriedades $(80 \%)$ si-
}

tuava-se no Agreste de Pernambuco. Os cultivos orgânicos atendiam às exigências da Instrução Normativa $n^{\circ} 007$, de 19/05/1999, do Ministério da Agricultura, Pecuária e Abastecimento (MAPA), que dispõe sobre a produção de produtos orgânicos vegetais e animais.

Para confirmar a identidade dos isolados foram realizados os seguintes testes diagnósticos: reação de hipersensibilidade em folhas de fumo, reação de Gram, crescimento anaeróbico, produção de pigmento fluorescente em meio King B (KMB), colônias amarelas e mucóides em meio extrato de levedura-dextrose-carbonato de cálcio (YDC), produção de urease, crescimento a $33^{\circ} \mathrm{C}$ em YDC, hidrólise do amido, produção de ácido a partir de arabinose e teste de patogenicidade em plantas de repolho (Schaad et al., 2001).

Sensibilidade de isolados de Xanthomonas campestris pv. campestris a antibióticos - A sensibilidade de 90 isolados de Xcc a antibióti$\cos$ foi determinada por antibiograma pelo método de difusão em ágar (Romeiro, 2001). Foram utilizados os antibióticos amoxicilina (AX) $10 \mu \mathrm{g}$; eritromicina (EI) $15 \mu \mathrm{g}$; estreptomicina (ET) $10 \mu \mathrm{g}$; gentamicina (GN) $10 \mu \mathrm{g}$; neomicina (NO) $30 \mu \mathrm{g}$; norfloxacin (NOR) $10 \mu \mathrm{g}$ e tetraciclina (TT) $30 \mu \mathrm{g}$. As placas foram mantidas em incubadora tipo BOD a $28^{\circ} \mathrm{C}$ por $24 \mathrm{~h}$, e avaliadas pela medição do halo de inibição das colônias, quando presente, em dois sentidos diametralmente opostos. O delineamento experimental foi inteiramente casualizado, com quatro repetições, sendo a unidade experimental constituída por um disco de antibiótico.

Adicionalmente, os isolados foram classificados em três grupos, de acordo com as reações de resistência (halo $\leq 14 \mathrm{~mm}$ ), média sensibilidade $(14 \mathrm{~mm}<$ halo $<20 \mathrm{~mm})$ e alta sensibilidade (halo $\geq 20 \mathrm{~mm}$ ), estabelecidas conforme valores médios dos halos de inibição referentes a cada antibiótico (Acar \& Goldstein, 1986).

Sensibilidade de isolados de Xanthomonas campestris pv. campestris ao cobre - Alíquotas de 5 $\mu \mathrm{l}$ das suspensões $\left(10^{8} \mathrm{UFC} \mathrm{mL}^{-1}\right)$ foram depositadas sobre o meio AN suplementado com sulfato de cobre $\left(\mathrm{CuSO}_{4} .5 \mathrm{H}_{2} \mathrm{O}\right)$, nas concentrações de $200 \mu \mathrm{g} / \mathrm{ml}^{-1}$ e de $50 \mu \mathrm{g} / \mathrm{ml}^{-1}$, sendo o sal diluído em água destilada por agitação durante 20 minutos e adicionado ao meio antes de sua autoclavagem (Quezado-Duval et al., 2003). A viabilidade dos isolados foi concomitantemente avaliada em meio AN não-suplementado com o agente químico. Todas as placas foram incubadas em BOD por $96 \mathrm{~h}$ a $28^{\circ} \mathrm{C}$. Na avaliação, foram considerados como resistentes isolados que apresentaram crescimento confluente. O percentual das populações referente a isolados resistentes foi calculado para cada concentração. O delineamento experimental foi inteiramente casualizado com 91 tratamentos e quatro repetições, sendo a unidade experimental constituída pelo ponto de crescimento da colônia.

Atividade de esterase de isolados de Xanthomonas campestris pv. campestris - Os isolados foram cultivados em meio 523 de Kado durante $36 \mathrm{~h}$ e repicados para quatro pontos eqüidistantes de uma placa de Petri contendo meio ágar-Tween 80 (Mariano et al., 2005). As placas foram mantidas em câmara de crescimento a $28^{\circ} \mathrm{C}$ por $48 \mathrm{~h}$, e avaliadas pela medição do halo de degradação do Tween 80 , quando presente, em dois sentidos diametralmente opostos. O delineamento experimental foi inteiramente casualizado, com três repetições, sendo a unidade experimental constituída por uma placa com quatro colônias bacterianas.

Reação de cultivares de brássicas à podridão-negra - Quatorze cultivares comerciais de brássicas (Tabela 1), sendo três de brócolos, um de couvemanteiga, quatro de couve-chinesa, quatro de couve-flor e dois de repolho, foram avaliados em relação ao isolado 'B21' de Xcc. Esse isolado foi obtido de planta de brócolos em sistema de produção orgânico, sendo selecionado com base na análise preliminar da variabilidade da população do patógeno (representante do grupo de similaridade com maior número de isolados) e maior severidade a plantas de repolho no teste de patogenicidade.

Plantas de brássicas com 30 dias, cultivadas em copos de plástico de $500 \mathrm{~mL}$ con- 


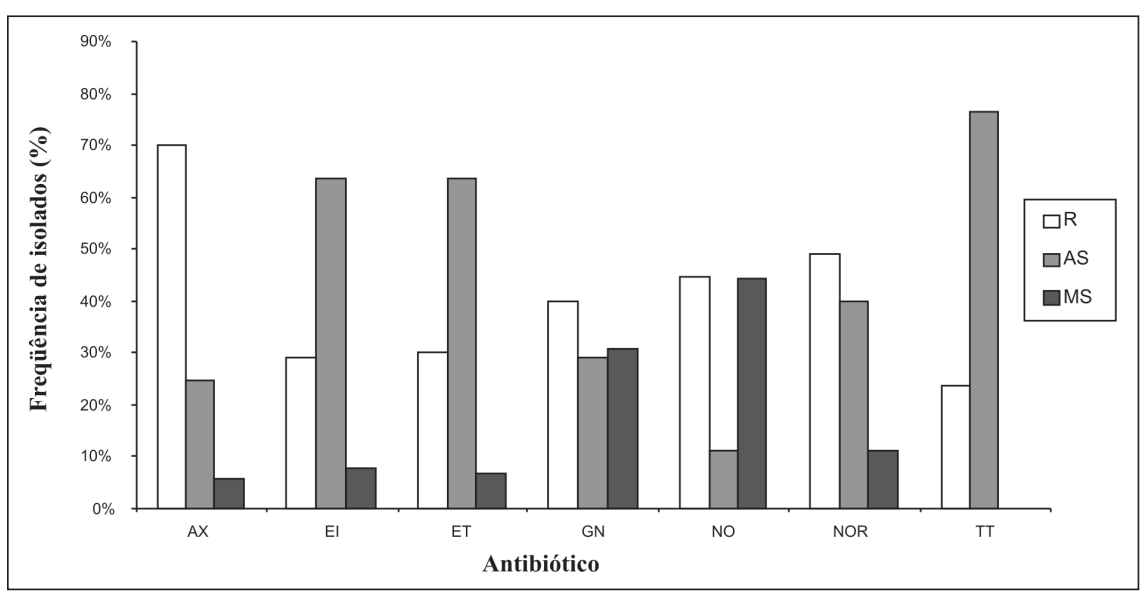

Figura 1. Reação de 90 isolados de Xanthomonas campestris pv. campestris a antibióticos: $\mathrm{AX}=$ amoxicilina; $\mathrm{EI}=$ eritromicina; $\mathrm{ET}=$ estreptomicina; $\mathrm{GN}=$ gentamicina; $\mathrm{NO}=$ neomicina; $\mathrm{NOR}=$ norfloxacina, $\mathrm{TT}=$ tetraciclina (reaction of 90 isolates from Xanthomonas campestris pv. campestris to the antibiotics: $\mathrm{AX}=$ amoxicilin; $\mathrm{EI}=$ eritromicin; $\mathrm{ET}=$ estreptomicin; $\mathrm{GN}=$ gentamicin; $\mathrm{NO}=$ neomicin; $\mathrm{NOR}=$ norfloxacin and $\mathrm{TT}=$ tetraciclin). Recife, UFRPE, 2007.

Tabela 1. Reação de cultivares de brássicas à podridão-negra, inoculados com o isolado 'B21' de Xanthomonas campestris pv. campestris em condições de casa de vegetação e avaliados 10 dias após a inoculação (reaction of brassica cvs. to the black rot, innoculated with the "B21" isolate of Xanthomonas campestris pv. Campestris under greenhouse conditions, evaluated 10 days after innoculation). Recife, UFRPE, 2007.

\begin{tabular}{|c|c|c|c|c|}
\hline Cultivar de brassica & $\begin{array}{l}\text { Período de } \\
\text { incubação } \\
\text { (dias) }^{1}\end{array}$ & $\begin{array}{c}\text { Incidência } \\
(\%)^{2}\end{array}$ & Severidade $^{3}$ & Reação 4 \\
\hline Brócolos Ramoso & $3,00 \mathrm{~d} 5$ & $100,00 \mathrm{a}$ & 46,33 a & AS \\
\hline Brócolos Ramoso & $3,83 \mathrm{bcd}$ & $100,00 \mathrm{a}$ & $7,00 \mathrm{bc}$ & MR \\
\hline Brócolos Precoce Piracicaba & $4,67 \mathrm{abc}$ & $83,33 \mathrm{~b}$ & 3,67 cde & MR \\
\hline Couve-manteiga Geórgia & $3,17 \mathrm{~cd}$ & $100,00 \mathrm{a}$ & $8,33 \mathrm{bc}$ & SU \\
\hline Couve-chinesa Híbrido AF 70 & $4,67 \mathrm{abc}$ & $83,33 \mathrm{~b}$ & $1,83 \mathrm{de}$ & AR \\
\hline Couve-chinesa Híbrido AF 72 & $5,50 a b$ & $100,00 \mathrm{a}$ & $1,67 \mathrm{e}$ & AR \\
\hline Couve-chinesa Híbrido AF 69 & $5,33 a b$ & $100,00 \mathrm{a}$ & $1,83 \mathrm{de}$ & AR \\
\hline Couve-chinesa Híbrido AF 66 & 6,17 a & $100,00 \mathrm{a}$ & $1,83 \mathrm{de}$ & AR \\
\hline Couve-flor Bola de Neve & $3,67 \mathrm{~cd}$ & $100,00 \mathrm{a}$ & 36,16 a & AS \\
\hline Couve-flor Piracicaba de Verão & $3,33 \mathrm{~cd}$ & $100,00 \mathrm{a}$ & $22,33 a b$ & AS \\
\hline Couve-flor Precoce Piracicaba & $3,83 \mathrm{bcd}$ & $100,00 \mathrm{a}$ & $6,67 \mathrm{~cd}$ & MR \\
\hline Couve-flor Híbrido Cindy & $3,83 \mathrm{bcd}$ & $83,33 \mathrm{~b}$ & 4,83 cde & MR \\
\hline Repolho Chato de Quintal & $3,67 \mathrm{~cd}$ & $100,00 \mathrm{a}$ & $16,50 a b$ & AS \\
\hline Repolho 60 Dias & $4,33 \mathrm{bcd}$ & $83,33 \mathrm{~b}$ & $4,50 \mathrm{cde}$ & MR \\
\hline C.V. (\%) & 10,95 & 7,00 & 34,85 & - \\
\hline
\end{tabular}

Período de incubação= número de dias entre a inoculação e o surgimento dos sintomas da doença; ${ }^{2}$ incidência $=$ porcentagem de plantas com sintomas da doença em relação ao total de plantas avaliadas; ${ }^{3}$ severidade final da doença $=$ estimada com o auxílio de escala diagramática com níveis de severidade de 1, 2, 4, 8, 16 e 32\% de área foliar infectada (adaptado de Azevedo et al., 2000); ${ }^{4}$ Reação das cultivares $=$ baseada no valor da severidade $(0,1-2,0 \%=$ altamente resistente (AR); 2,1-8,0\%= medianamente resistente (MR); 8,1-16,0\%= suscetível (SU); $>16,1 \%=$ altamente suscetível (AS); ${ }^{5}$ Médias de seis repetições (médias transformadas log ( $\mathrm{x}$ $+1)$ ) (incubação) ou arcseno $(x+1)$ (severidade); Médias seguidas pela mesma letra na vertical, não diferem estatisticamente pelo teste de Duncan a 5\% de probabilidade;

tendo mistura de solo/substrato $(1: 1 \mathrm{v} / \mathrm{v})$, em condições de casa de vegetação, foram inoculadas por pulverização com suspensões de $X c c$ contendo $1 \times 10^{8} \mathrm{UFC} \mathrm{mL}^{-1}$. As plantas foram mantidas em câmara úmida por 24 horas antes e após a inoculação. O delineamento experimental foi inteiramente casualizado, com seis repetições, sendo a unidade experimental constituída por duas folhas da planta.
As plantas foram avaliadas diariamente, até 10 dias após a inoculação, determinando-se os componentes epidemiológicos: período de incubação (PI) (número de dias entre a inoculação e o surgimento dos sintomas); incidência (INC) (porcentagem de plantas com sintomas da doença em relação ao total de plantas avaliadas); e severidade final (SEVF) (estimadas com o auxílio de escala diagramática com níveis de severidade de $1 ; 2 ; 4 ; 8 ; 16$ e $32 \%$ de área foliar infectada (adaptado de Azevedo et al., 2000)). O valor da SEVF foi utilizado para agrupar as cultivares em quatro classes: $0,1-2,0 \%=$ altamente resistente (AR); $2,1-8,0 \%=$ medianamente resistente (MR); $8,1-16,0 \%=$ suscetível (SU); $>16,1 \%=$ altamente suscetível (AS).

Os dados de sensibilidade a antibióticos e ao cobre e da atividade de esterase foram submetidos à análise de correlação de Pearson $(\mathrm{p}=0,05)$ e os isolados de $X c c$ agrupados pela análise da distância Euclidiana por ligações simples.

Os dados de PI, INC e SEVF também foram submetidos à análise de correlação de Pearson $(\mathrm{p}=0,05)$ e análise de variância, sendo as médias comparadas pelo teste de Duncan $(\mathrm{p}=0,05)$.

\section{RESULTADOS E DISCUSSÃO}

Foram obtidos 90 isolados bacterianos, sendo 34 de couve (C), 26 de brócolos (B), 17 de repolho (R), 12 de couve-flor (CF) e 1 de couve-chinesa (CC), identificados como Xcc (Schaad et al., 2001). Constatou-se grande variabilidade na sensibilidade dos isolados aos antibióticos. Com base na classificação de Acar \& Goldstein (1986), 20 isolados (B1, B2, B11, B18, B19, B26, B27, B32, C2, C8, C20, C26, C27, C35, C39, C40, C42, CF10, CF11 e R13) foram resistentes a todos os antibióticos, apenas dois isolados $(\mathrm{C} 31 \mathrm{e}$ CF1) apresentaram alta sensibilidade a todos os antibióticos, enquanto cinco isolados (CC1, CF2, CF4, CF6 e CF13) só não apresentaram alta sensibilidade à amoxicilina. Variabilidade na reação a esses antibióticos também foi verificada em relação a 25 isolados de $X c c$ de sistema convencional de brássicas no estado de Pernambuco, 
onde apenas um isolado foi resistente a todos os antibióticos (Costa et al., 2001).

A maioria dos isolados apresentou alta sensibilidade à tetraciclina $(76,6 \%)$, eritromicina $(63,3 \%)$ e estreptomicina $(63,3 \%)$; resistência à amoxicilina (70\%), gentamicina $(40,0 \%)$ e norfloxacin $(45,5 \%)$; e média sensibilidade $(44,4 \%)$ ou resistência $(44,4 \%)$ à neomicina (Figura 1). Em sistema convencional, estudando 25 isolados de Xcc Costa et al. (2001) verificaram que a maioria apresentou resistência à neomicina, resistência ou média sensibilidade à estreptomicina e alta sensibilidade à tetraciclina. Adhikari \& Basnyat (1999), também em sistema de cultivo convencional, detectaram variabilidade dessa bactéria a antibióticos, onde a maioria apresentou sensibilidade à tetraciclina e resistência à gentamicina e eritromicina. A alta sensibilidade aos antibióticos tetraciclina, estreptomicina e eritromicina apresentada pela maioria dos isolados, deve-se provavelmente ao fato de nenhum desses antibióticos ser utilizado no sistema de produção orgânico. Isto foi devidamente demonstrado por Costa et al. (2001) com relação à estreptomicina em sistema convencional, no qual os isolados apresentaram resistência ou média suscetibilidade a esse antibiótico. No entanto, mesmo sem a utilização de antibióticos nesse sistema, alguns isolados apresentaram resistência, como no caso da amoxicilina, o que pode ser explicado pela ocorrência de resistência natural em bactérias (Romeiro, 2005).

Cinqüenta e cinco isolados foram resistentes ao sulfato de cobre na concentração de $50 \mathrm{mg} / \mathrm{mL}$, mas todos foram sensíveis ao produto na concentração de 200 mg/mL. Resistência a teores baixos de cobre, como a detectada no presente trabalho, foi verificada também em isolados de Xanthomonas spp. associadas à mancha-bacteriana do tomate (Quezado-Duval et al., 2003) e pimentão (Aguiar et al., 2000), em sistemas de produção convencional. A presença de isolados de Xcc com resistência ao sulfato de cobre foi inesperada, pois esse produto não é utilizado pelos agricultores no controle da podridão-negra em sistema de produção orgânico, sugerindo que esses isolados podem ter sua origem

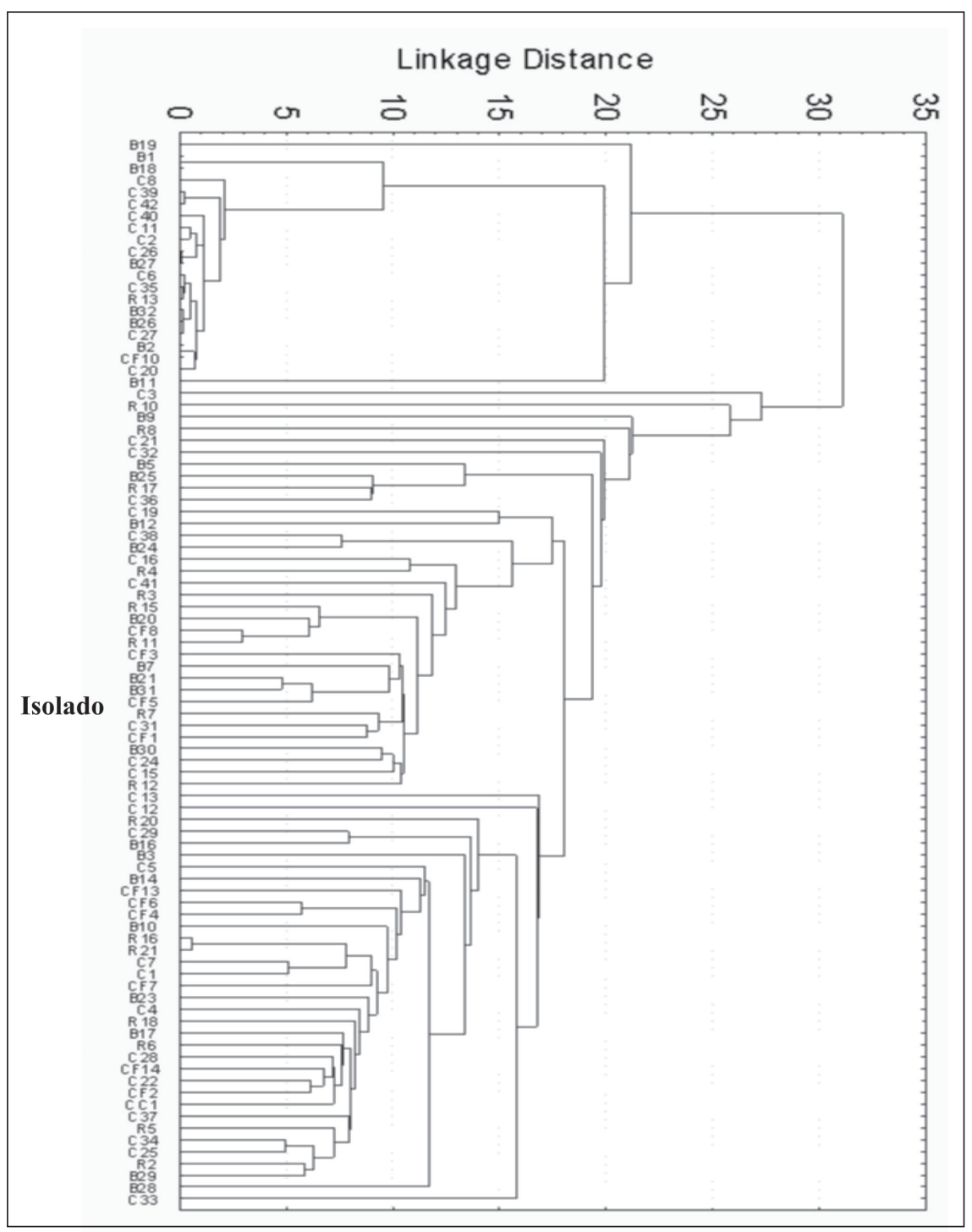

Figura 2. Agrupamento de 90 isolados de Xanthomonas campestris pv. campestris de diferentes tipos de brássicas, baseado na análise Euclidiana por ligação simples, considerando sensibilidade a antibióticos e atividade de esterase (Grouping of 90 isolates of Xanthomonas campestris pv. campestris to brassica species, based on the Euclidian analysis, considering the sensibility to antibiotics and activity of the

em brássicas produzidas no sistema de produção convencional. Na maioria das áreas estudadas, o sistema convencional precedeu o orgânico, que apresenta plantios sucessivos de brássicas, cujas mudas são produzidas em canteiros.

Dos 90 isolados analisados, 92,22\% apresentaram atividade de esterase, indicando, no entanto, baixa variabilidade. Resultado similar foi obtido por Costa et al. (2001) em relação a 20 isolados dessa bactéria oriundos de sistema de produção convencional, onde todos apresentaram atividade esterásica.

A ausência de correlação significativa entre as variáveis analisadas no es- tudo de variabilidade pode indicar que as características são determinadas por diferentes grupos de genes e a população seja espontaneamente recombinada. Embora as informações sobre o patossistema $X c c$-brássicas em sistema de manejo orgânico ainda sejam escassas, há existência de diversidade genética na população em estudo. Os dois tipos de diversidade genética que contribuem para a estrutura genética são as diversidades gênica e genotípica. A diversidade genotípica está relacionada com o número e a freqüência dos genótipos multilocus ou indivíduos geneticamente distintos em uma popula- 
ção, enquanto que a diversidade gênica se refere ao número e freqüência de alelos em locos individuais numa população. Nos patógenos com reprodução assexual, como no caso em estudo, medidas de diversidade genotípicas são mais significantes do que medidas de diversidade gênica, porque a maioria da diversidade genética é distribuída entre linhagens clonais (McDonald \& Linde, 2002).

A análise Euclidiana por ligação simples, utilizando os dados de sensibilidade a antibióticos e cobre e atividade de esterase, permitiu a distinção de sete grupos de similaridade de $X c c$ considerando a distância de ligação 20 (Figura 2). Os isolados B19, C3, R10, B9 e R8 constituíram cinco grupos de similaridade distintos. Os isolados B1, B18, B8, C39, C42, C40, C11, C2, C26, B27, C6, C35, R13, B32, B26, C27, B2, CF10, C20 e B11 formaram outro grupo de similaridade e os demais isolados (59) formaram um únicogrupo, confirmando a existência de alta variabilidade entre os isolados oriundos de sistema de produção orgânico. Verificou-se dentro de um mesmo grupo de similaridade isolados de hospedeiros diferentes, indicando não ser o tipo de hospedeiro de origem o fator que influencia na variabilidade. A causa da variabilidade entre os isolados de Xcc pode estar associada à adaptação da bactéria às diferentes espécies de brássicas e/ou cultivares de uma mesma espécie que são plantadas numa mesma área pelos agricultores das Zonas da Mata e Agreste de Pernambuco. A procedência das sementes, que podem carrear a bactéria, utilizadas na região também pode ser um possível fator envolvido na variabilidade, tendo em vista que são utilizadas sementes produzidas por várias empresas. Outra hipótese a ser considerada é a ocorrência de eventos de recombinação genética entre populações filogeneticamente relacionadas.

Na análise da reação das 14 cultivares de brássicas ao isolado 'B21' de Xcc foram detectadas correlações significativas $(\mathrm{P}=0,05)$ entre todas as variáveis analisadas. As correlações negativas entre o PI e INC e SEVF indicam que a quantidade de podridão-negra está inversamente relacionada ao tempo de início dos sintomas, enquanto que as correlações positivas entre INC e SEVF indicam a dependência dessas variáveis no desenvolvimento da doença.

As cultivares diferiram significativamente entre si em relação a todas as variáveis analisadas. Foram formados quatro, dois e cinco grupos distintos respectivamente para as variáveis PI, INC e SEVF (Tabela 1). Dentro de um mesmo grupo foram encontrados diferentes cultivares de brássicas.

Os maiores valores de SEVF foram verificados em brócolos Ramoso, couve-flor Bola de Neve e Piracicaba de Verão e repolho Chato de Quintal, classificados como altamente suscetíveis à podridão-negra. Os híbridos de couvechinesa AF 70, AF 72, AF 69 e AF 66 mostraram-se altamente resistentes à doença, enquanto que brócolos Ramoso e Precoce Piracicaba, couve-flor Precoce de Piracicaba e Híbrido Cindy e repolho 60 Dias foram medianamente resistentes (Tabela 1). Em levantamento da intensidade da podridão-negra em cultivos de brássicas no sistema de produção orgânico realizado em 2001, a severidade da doença foi significativamente maior em couve-chinesa do que brócolos, couve-flor e couve-manteiga (Peruch et al., 2006). No catálogo de produtos da empresa de sementes, os híbridos de couve-chinesa mencionados acima não são citados como portadores de resistência/tolerância à podridão-negra (Sakata, 2007).

Para o controle da podridão-negra são indicados comercialmente, visando o sistema de produção convencional, com algum nível de resistência ou tolerância à doença as cvs. de repolhos. Máster, Máster AG-325, Chumbinho, Louquinho e os híbridos ESALQ-84, Mogiano, Saikô, Caribe, HG 18, YRRampo, YR-Ranshu, Nozomi, Matsukase, Kenzan, Fuyutoyo, Blue Vantage, Dynamo, Red Ball, Green Valley e Itiro; as cvs. de couve-flor Verona AG-184, Verona AG-284, Flórida e Santa Elisa-2 e os híbridos Ikuta, Jaraguá, Miayai, Shiromaru I, II e III, Sharon, Sarah e Júlia; as cvs. de brócolos Condor, Precoce Piracicaba Verão, Ramoso Santana, Flórida e Baron; e o híbrido de couve-manteiga F1 Top Bunch (Maringoni, 1997; Sakata, 2007;
Syngenta, 2007). No entanto, já foram relatadas diversas raças do patógeno (Vicente et al., 2001; Kamoun et al., 1992) indicando que a variabilidade patogênica existente na população de $X c c$ poderá ocasionar reações diferentes dessas cultivares à podridão-negra.

A falta de cultivares adaptadas aos sistemas de produção orgânica tem sido destacada como uma das sérias limitações para o manejo de doenças em hortaliças e outras culturas (Bueren, 2002). Evidenciou-se nessa pesquisa que os agricultores dispõem no mercado de cultivares de couve-chinesa, brócolos, couve-flor e repolho com resistência ou moderada resistência à podridão-negra, cujo cultivo poderá reduzir as perdas de produção causadas pela doença. Não se deve esquecer a possibilidade de quebra da resistência, pela ocorrência de variabilidade patogênica na população de Xcc.

\section{AGRADECIMENTOS}

À Sakata pelo fornecimento de sementes.

\section{REFERÊNCIAS}

ACAR JF; GOLDSTEIN FW. 1986. Disk susceptibility test. In: RORIAN V. (ed). Antibiotics in laboratory medicine. London: Willians \& Wilkins. p. 27-62.

ADHIKARI TB; BASNYAT R. 1999. Phenotypic characteristics of Xanthomonas campestris pv. campestris from Nepal. European Journal of Plant Pathology 105: 303-305.

AGUIAR L; KIMURA O; CASTILHO AMC; CASTILHO KSC; RIBEIRO RLD; ANIBAF; CARMO MGF. 2000. Resistência ao cobre em isolados nacionais de Xanthomonas campestris pv. vesicatoria de pimentão e tomateiro. Agronomia 34: 78-82.

AZEVEDO SS; MARIANO RLR; MICHEREFF SJ. 2000. Levantamento da intensidade da podridão-negra e da alternariose do repolho no Agreste de Pernambuco e determinação do tamanho das amostras para quantificação dessas doenças. Summa Phytopathologica 26: 299-305.

BUEREN TL. 2002. Organic plant breeding and propagation: concepts and strategies. Wageningen: Wageningen Agricultural Unviersity. 209p (Tese doutorado).

CASELA CB; GUIMARÃES FB. 1996. Especialização fisiológica de fungos fitopatogênicos. Revisão Anual de Patologia de Plantas 4: 75-93.

COSTA VSO; MARIANO RLR; MICHEREFF SJ. 2001. Variabilidade de isolados de Xanthomonas campestris pv. campestris no Estado de Pernambuco. Summa Phytopathologica 2: 182-189. 
HENZ GP; REIFSCHNEIDER FJB; TAKATSU A; GIORDANO LB. 1987. Identificação de fontes de resistência a Xanthomonas campestris pv. campestris em Brassicas. Horticultura Brasileira 5: 18-20.

KAMOUN S; KAMDAR HV; TOLA E; KADO CI. 1992. Incompatible interactions between crucifers and Xanthomonas campestris involve a vascular hypersensitive response: role of the hrpX locus. Molecular Plant-Microbe interactions 5: 22-23.

MARIANO RLR; SILVEIRA EB; ASSIS SMP; GOMES AMA. Identificação de bactérias fitopatogênicas. In: MARIANO RLR; SILVEIRA EB (coords). 2005. Manual de práticas em fitobacteriologia. Recife: UFRPE. p.67-111.

MARINGONI AC. 1997. Doenças das crucíferas (brócolis, couve, acelga, couve-flor, rabanete, repolho e rúcula). In: KIMATI H; AMORIM L; BERGAMIN FILHO A; CAMARGO LEA; REZENDE JAM. (eds). Manual de fitopatologia: doenças das plantas cultivadas. 3. ed. São Paulo: Agronômica Ceres. p. 315324.

MCDONALD BA; LINDE C. 2002. The population genetics of plant pathogens and breeding strategies for durable resistance. Euphytica 124: 163-180.
PERUCH LAM; MICHEREFF SJ; ARAÚJO IB. 2006. Levantamento da intensidade da alternariose e da podridão negra em cultivos orgânicos de brássicas em Pernambuco e Santa Catarina. Horticultura Brasileira 24: 464-469.

QUEZADO-DUVAL AM; GAZZOTO FILHO A; LEITE JUNIOR RP; CAMARGO LEA. 2003. Sensibilidade a cobre, estreptomicina e oxitetraciclina em Xanthomonas spp. associadas à mancha-bacteriana do tomate para processamento industrial. Horticultura Brasileira 21: 670-675.

RODRIGUES VJLB; MICHEREFF SJ; AGUIAR FILHO MR; SILVA LGC; BIONDI CM. 2004. Epidemiologia comparativa da alternariose em cultivares de brássicas sob cultivo convencional e orgânico. Summa Phytopathologica 30: 226-233.

RODRIGUES NETO J; MALAVOLTA JUNIOR VA. 1995. Doenças causadas por bactérias em crucíferas. Informe Agropecuário 17: 56-59.

ROMEIRO RS. 2001. Métodos em bacteriologia de plantas. Viçosa: UFV. 279p.

ROMEIRO RS. 2005. Bactérias fitopatogênicas. Viçosa: UFV. 417p.

SAKATA. Catálogo de produtos. Brássicas. Disponível em:<http://sakata.com.br/ ? action $=$ busca $\&$ buscar_por $=$ cruc EDferas\&filtro=todos $>$. Acesso em: 27 de out. 2007.
SCHAAD NW; JONES JB.; CHUN W (eds.). 2001. Laboratory guide for identification of plant pathogenic bacteria. St. Paul: APS Press. 372p.

SYNGENTA. Produtos. Brássicas. Disponível em: <http://www.syngentaseeds.com.br/ novosite/brassicas.asp>. Acesso em: 27 de out. 2007.

VAN BRUGGEN A. 2001. Switching over to organic farming systems: consequences for plant pathological research. Summa Phytopathologica 27: 145.

VICENTE JG; CONWAY J; ROBERTS SJ; TAYLOR JD. 2001. Identification and origin of Xanthomonas campestris pv. campestris races and related pathovars. Phytopathology 91: 429-499.

WILLER H; YUSSEFI M. 2005. The world of organic agriculture. Statistics and emerging trends. Bonn: International Federation of Organic Movement (IFOAM) \& Research Institute of Organic Agrivulture FiBL. 167p. 